\title{
Mass Spectrometric Measurement of Changes in Protein Hydrogen Exchange Rates that Result from Point Mutations
}

\author{
Richard S. Johnson* \\ Department of Biochemistry, University of Washington, Seattle, Washington, USA
}

\begin{abstract}
Point mutations, as well as additions or deletions of entire domains, are frequently produced to study protein function; however, to infer function from mutant proteins, it is imperative that their structural integrity be verified. Although detailed structural studies can be performed by using NMR or crystallography, for practical reasons mutant proteins usually are characterized by using less rigorous techniques. Here it is shown that measurement of hydrogen exchange rates via electrospray ionization mass spectrometry is a sensitive and generally applicable method for detection of conformational or dynamic changes that result from point mutations. Hydrogen exchange experiments were performed on a bacterial phosphocarrier protein (HPr) and two variants produced by conversion of either serine-46 to aspartic acid (S46D) or serine-31 to alanine (S31A), where the differences in the $\Delta G$ of folding relative to the wild type were 1.5 and $0.5 \mathrm{kcal} / \mathrm{mol}$, respectively. Whereas no significant differences were found for the intact mutant and wild-type proteins, changes in deuterium incorporation could be detected within specific regions produced by peptic proteolysis of the deuterium-labeled proteins. Thus, energetically small changes in conformation (or dynamics) that result from point mutations can be characterized by mass spectrometric measurements of hydrogen exchange rates. Furthermore, these changes can be localized to specific regions within the protein. (J Am Soc Mass Spectrom 1996, 7, 515-521)
\end{abstract}

$\mathrm{T}$ The use of electrospray ionization mass spectrometry (ESI/MS) [1] for the measurement of hydrogen isotope exchange was first demonstrated by Katta and Chait $[2,3]$ in denaturation studies of bovine ubiquitin and hen lysozyme. More recently, ESI/MS was used to characterize folding intermediates of lysozyme [4] as well as to study the influence of the molecular chaperone GroEL on the folding of $\alpha$ lactalbumin [5]. A correctly folded conformer of a synthetic protein has been differentiated from its unfolded form partly on the basis of its slower deuterium incorporation as measured by ESI/MS [6]. Anderegg and Wagner [7] have described intriguing experiments where changes in deuterium incorporation were observed for a recombinant src-SH2 domain upon binding to various phosphopeptides. Because the NMR and $x$-ray crystal structures of the bound and unbound $\mathrm{SH} 2$ domains were not markedly different, the differences in deuterium incorporation rates most likely were due to changes in protein dynamics. Most of these studies were carried out in solvents that are compatible with ESI/MS; however, such conditions are not suitable for most proteins (low salt, no deter-

Address reprint requests to Dr. Richard S. Johnson, Immunex Corporation, 51 University Street, Seattle, WA 98101-2936.

"Current address: Immunex Corporation, Seattle, WA. gent, etc.). Moreover, these studies on intact proteins do not provide detailed information with regard to specific changes within the protein.

To address this latter shortcoming, tandem mass spectrometry was used to obtain exchange rates for individual residues within two large ( 26 and 32 residue) helical peptides [8]. However, recent experiments have shown that the proton mobility within smaller peptide ions is sufficiently rapid so as to scramble the deuterium labeling [9]. Perhaps larger peptide ions form helical structures in the gas phase and contain intramolecular hydrogen bonds that would inhibit deuterium scrambling. Indeed, secondary and possibly tertiary structures have been detected within gas-phase protein ions [10], but it is not clear that these or any other gas-phase protein structures bear any resemblance to those in solution. Thus, tandem mass spectrometry of deuterium-labeled proteins may prove useful for the characterization of gas-phase secondary structures, but the application of this technique for proteins in solution appears to be problematic.

Alternatively, Zhang and Smith [11] modified an earlier tritium method $[12,13]$ that permits intermediate resolution of the individual amide hydrogen exchange rates. By dissecting a protein with a protease, the deuterium incorporation within segments defined by protease cleavage can be measured via liquid chro- 
matography-mass spectrometry (LC/MS) by using a flowing fast-atom bombardment ionization interface. The same laboratory has pursued this methodology in the study of human lens crystallines [14], rabbit muscle aldolase and its interaction with a Band III peptide [15], and cytochrome $c$ binding to membranes [16]. A modification of this method enabled deuterium incorporation to be measured for apo- and holomyoglobin, where it was found that two regions that are separate in sequence but adjacent in the three-dimensional structure appeared to exhibit identical hydrogen exchange rates regardless of the presence of the heme group [17]. These data demonstrated that mass spectrometric measurement of deuterium incorporation, that is, hydrogen exchange, can be performed by using electrospray ionization and that this method is sufficiently sensitive to detect changes in conformation or dynamics upon removal of the noncovalently bound heme group. However, the difference in the $\Delta G$ of folding $(\Delta \Delta G)$ between apo- and holomyoglobin is significant (approximately $5.5 \mathrm{kcal} / \mathrm{mol}$ [18]), and the question remains whether more subtle structural changes can be detected.

Site-directed mutagenesis provides protein chemists with an important tool to probe the functional significance of individual residues. In addition to the mutation of single residues, entire regions that correspond to suspected functional domains can be deleted or inserted. In either case, the mutagenized protein should be characterized to confirm that the three-dimensional structure has not been altered unexpectedly (e.g., [19-21]). In the absence of structural data, functional interpretations are suspect. For well-behaved proteins, a complete structural analysis can be carried out by using NMR or crystallography, but in most cases proteins are too large, insoluble, or glycosylated to permit such studies. Instead less specific methods are often used-circular dichroism, antibody binding, susceptibility to proleolysis, or fluorescence studies. Such techniques give only global pictures of the mutant proteins, and there is necd for more detailed information. In the present study, the phosphocarrier protein $\mathrm{HPr}$ [22] from E. coli is compared with two mutant proteins. In one case, the serine at position 46 has been changed to aspartic acid (S46D), which results in a stabilization such that the difference in the $\Delta G$ of folding compared to the wild-type protein $(\Delta \Delta G)$ is 1.5 $\mathrm{kcal} / \mathrm{mol}$ ( $R$. Klevit, personal communication). A second mutant produced by conversion of serine at position 31 to alanine (S31A) was found to be destabilized by $0.5 \mathrm{kcal} / \mathrm{mol}$ compared to the wild-type protein [23]. Deuterium incorporation was measured for the wild-type and the two mutant proteins by using LC/MS with an electrospray interface, and it is shown that this is a sensitive technique for identification of regions within proteins that exhibit conformational or dynamic changes that result from single point mutations.

\section{Methods}

Wild-type and mutant E. coli HPr (S31A and S46D) were kindly provided by Dr Rachel Klevit at the University of Washington.

For exchange experiments, HPr ( 9 nmol) was first solubilized in $40 \mu \mathrm{L}$ of $200-\mathrm{mM}$ pH 6.3 potassium phosphate in $\mathrm{H}_{2} \mathrm{O}$ (buffer $\mathrm{A}$ ) at room temperature for $30 \mathrm{~min}$. Deuterium exchange-in was carried out at room temperature and was initiated by the addition of $760-\mu \mathrm{L} \mathrm{D} \mathrm{D}_{2} \mathrm{O}$ to the solubilized protein. The measured $\mathrm{pD}$ (no isotopic correction) was 6.8. Aliquots of $36 \mu \mathrm{L}$ were quenched at various times by the addition of 36 $\mu \mathrm{L}$ of $500-\mathrm{mM}$ pH 2.6 potassium phosphate in water (buffer B). Quenched samples were immediately frozen in liquid nitrogen and stored at $-70^{\circ} \mathrm{C}$ until they were analyzed by LC/MS.

The percent deuterium incorporation was calculated by comparison with two controls-a zero time point and the completely deuterated protein. 'l'he zero time point was obtained by dissolving 9-nmol HPr in $40 \mu \mathrm{L}$ of buffer $\mathrm{A}$ and adding $\mathrm{D}_{2} \mathrm{O}(760 \mu \mathrm{L})$ previously acidified with $800-\mu \mathrm{L}$ buffer B. Aliquots of $72 \mu \mathrm{L}$ were frozen. The completely deuterated protein was produced by incubation in deuterated buffer at $\mathrm{pD} 6.8$ for $30 \mathrm{~min}$ at $100^{\circ} \mathrm{C}$ followed by incubation at $60^{\circ} \mathrm{C}$ for an additional $5 \mathrm{~h}$. The completely deuterated protein was quenched as described in the preceding text and stored at $-70{ }^{\circ} \mathrm{C}$. The percent incorporation of deuterium $(D \%)$ for either peptides or the intact protein was calculated as [11]

$$
D \%=\left(m_{t}-m_{0 \%}\right) /\left(m_{100 \%}-m_{0 \%}\right) \times 100,
$$

where $m_{t}$ is the peptide (or protein) mass at time $t$, $m_{0 \%}$ is the mass of the peptide at time zero, and $m_{100 \%}$ is the peptide mass at infinite time (completely deuterated).

LC/MS was performed on an API-III triple quadrupole mass spectrometer (Perkin-Elmer Sciex, Norwalk, CT) equipped with a nebulization-assisted electrospray ionization source. An Applied Biosystems, Inc. (ABI; Foster City, CA) syringe pump (model 140A) was used to generate 15-min high-performance liquid chromatography (HPLC) gradients of $0-60 \%$ acetonitrile that contained $0.02 \%$ trifluoroacetic acid $(\mathrm{pH} 2.8)$ at $75 \mu \mathrm{L} / \mathrm{min}$ through a $1-\times 30-\mathrm{mm} \mathrm{C}_{8}$ column. The solvent was directed through a coil of narrow bore stainless steel tubing that was immersed in an ice bath prior to a Rheodyne (Cotati, CA) injector and the column. A postcolumn splitting tee was used to divert approximately two-thirds of the effluent to an $\mathrm{ABI}$ model 785A UV detector; the remainder of the effluent was directed toward the inass spectrometer. Mass spectra were acquired by using a step size of $0.2 \mathrm{u}$ with a dwell time of $1 \mathrm{~ms}$ at unit resolution. No efforts were made to reduce back-exchange during the electrospray process, although the $100 \%$ controls generally showed an overall back-exchange of about $40-50 \%$ 
during peptic digestion, HPLC, and ionization. Because $\mathrm{D}_{2} \mathrm{O}$ is washed away with the buffer salts, peptides are electrosprayed only in the presence of $\mathrm{H}_{2} \mathrm{O}$, acetonitrile, trifluoroacetic acid, and any coeluting peptides. Thus, water is in a vast excess over any coeluting partially deuterated peptide, and intermolecular scrambling of label during electrospray ionization (ESI) would lead predominantly to a loss of deuterium, that is, the $100 \%$ and $0 \%$ controls would approach identity.

Partially deuterated samples were individually removed from the freezer, thawed, and immediately proteolyzed by the addition of pepsin with an enzyme to substrate ratio of $1: 1$ by weight. After $5 \mathrm{~min}$ of peptic digestion on ice the sample was injected onto the $C_{8}$ column and the acetonitrile gradient was started after $5 \mathrm{~min}$ of desalting. The column was disconnected from the mass spectrometer for the duration of the desalting period and reconnected prior to initiation of the acetonitrile gradient. The molecular weights of partially deuterated peptides were determined by calculation of centroids of the peak envelope.

Peptic peptides were identified by using tandem mass spectrometry, where the known sequence of $\mathrm{HPr}$ was used as a template to aid in data interpretation. Tandem mass spectrometry was performed by using a step of $0.25 \mathrm{u}$ and a dwell time of $1 \mathrm{~ms}$ with a resolution in the first and third quadrupoles sufficient to transmit 2-3-u wide windows. Precursor ions were accelerated to kinetic energies that ranged from 15 to $25 \mathrm{eV}$ and collisionally activated with argon in the second quadrupole. The instrument control software reports the collision gas pressure as a "gas thickness," which was typically set to $2.5 \times 10^{14}$ atoms of argon per cubic centimeter. Data interpretation was carried out via a computer program written in-house (Taylor, J. A.; Walsh, K. A.; Johnson, R. S., manuscript in preparation).

\section{Results}

To assess the reproducibility of this method to detect changes in protein conformation or dynamics, repeat measurements were made on the wild-type protein. Figure 1a shows the data obtained for the intact protein and Figure $1 \mathrm{~b}$ depicts the results for one of the peptides obtained after brief peptic digestion of the partially deuterium-labeled protein. Mass spectrometric measurements of deuterium-labeled proteins are reproducible. This result also has been verified by Zhang and Smith, who reported measurement errors of $\pm 5 \%$ [11].

Figure 2 shows the deuterium incorporation into intact wild-type (dark bars) and S46D HPr (light bars); no significant differences could be detected. In contrast, dissection of the proteins with pepsin prior to LC/MS analysis makes it possible to accentuate those regions that exhibit relatively small changes that could not be detected at the level of the whole protein. In the
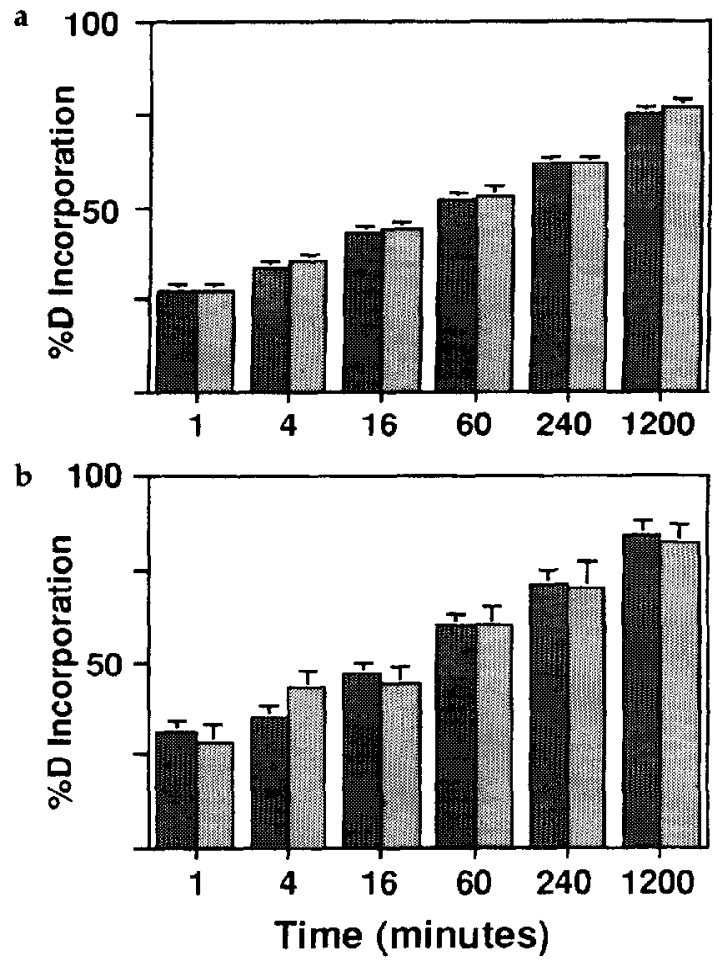

Figure 1. Reproducibility of measurement. Two measurements (represented by light and dark bars) were made two weeks apart for wild-type HPr from E. coli. The percent deuterium incorporation was measured at various times after the addition of $D_{2} \mathrm{O}$ for (a) the intact protein and (b) the peptide that encompasses positions 33-47. See the Methods section for experimental details.

S46D mutant, one of the more significant differences was observed for the peptic peptide that encompasses positions 33-47 (Figure 3b), where the wild-type protein (dark bars) was $70 \%$ deuterated within $240 \mathrm{~min}$, but the mutant (light bars) was only $50 \%$ labeled. This difference corresponds to 2.8 deuterons out of a total of

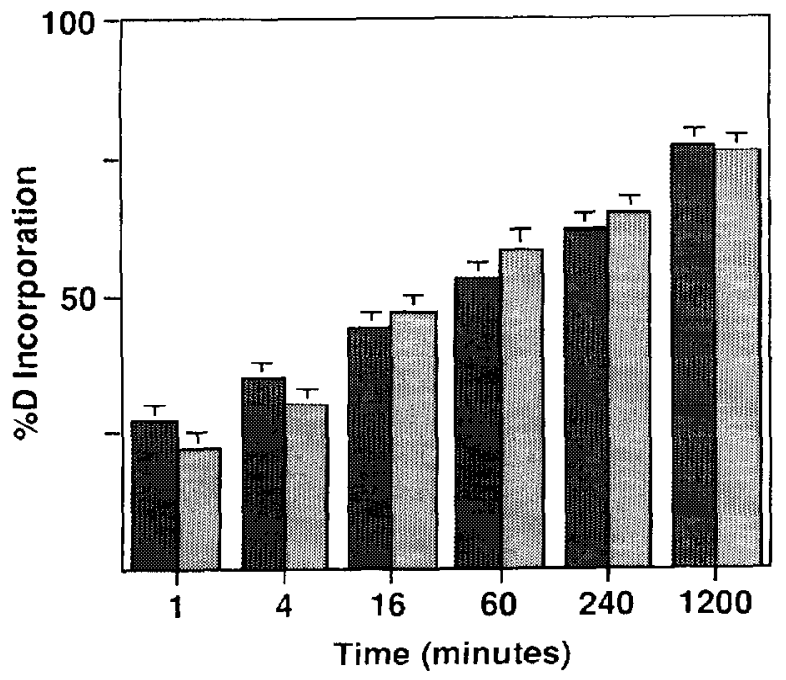

Figure 2. Percent deuterium incorporation for the intact wildtype $E$. coli HPr (dark bars) and the $546 \mathrm{D}$ mutant (light bars). See the Methods section for experimental details. 

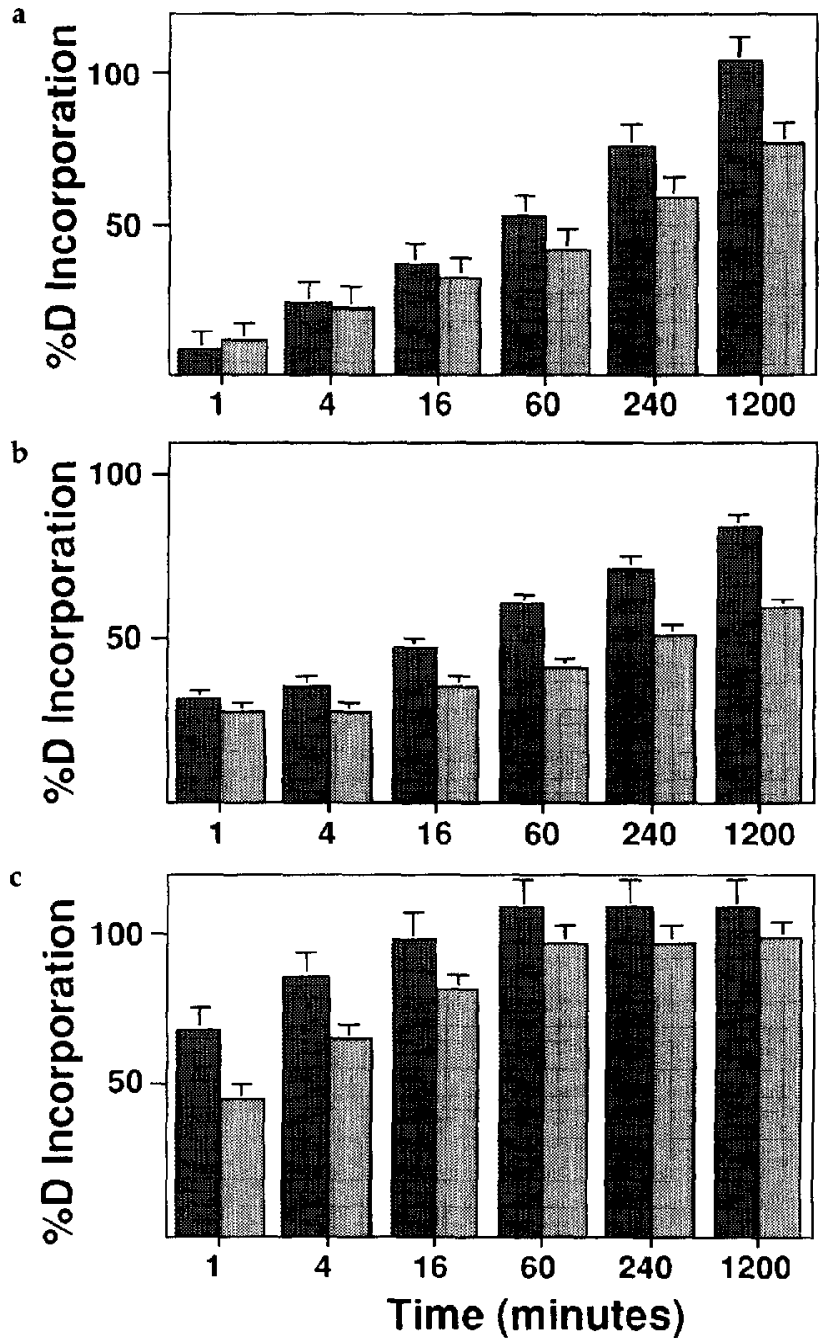

Figure 3. Peptides derived from the wild-type E. coli HPr (dark bars) and S46D mutant (light bars) that exhibit substantial differences in deuterium incorporation rates. These peplides encompass positions (a) 23-32, (b) 33-47, and (c) 48-58. See the Methods section for experimental details.

14 amide hydrogens. Significant differences also were observed for the peptides that encompass positions 23-32 and 48-58 (Figure $3 a$ and c). Note that the S46D mutant is more stable than the wild-type protein, and deuterium incorporation within these regions occurs at a slower rate for the mutant, as expected. In contrast, the remaining peptic peptides appear to be unchanged (Figure 4), although the 1200-min time point for the wild-type peptide that encompass positions $1-5$ is anomalously high.

The $331 \mathrm{~A}$ mutant, which is $0.5 \mathrm{kcal} / \mathrm{mol}$ less stable than the wild-type protein, also was examined. Most of the peptic peptides derived from this mutant were not significantly different from those obtained from the wild-type protein (e.g., Figure 5b). However, the peptide 33-47 obtained from the lower stability mutant incorporated deuterium at a slightly higher rate (Figure 5a). a

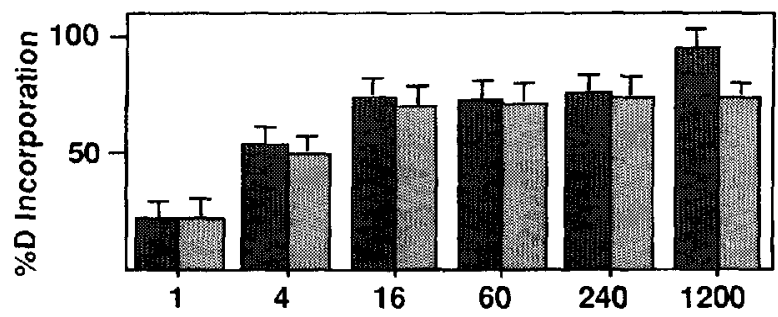

b
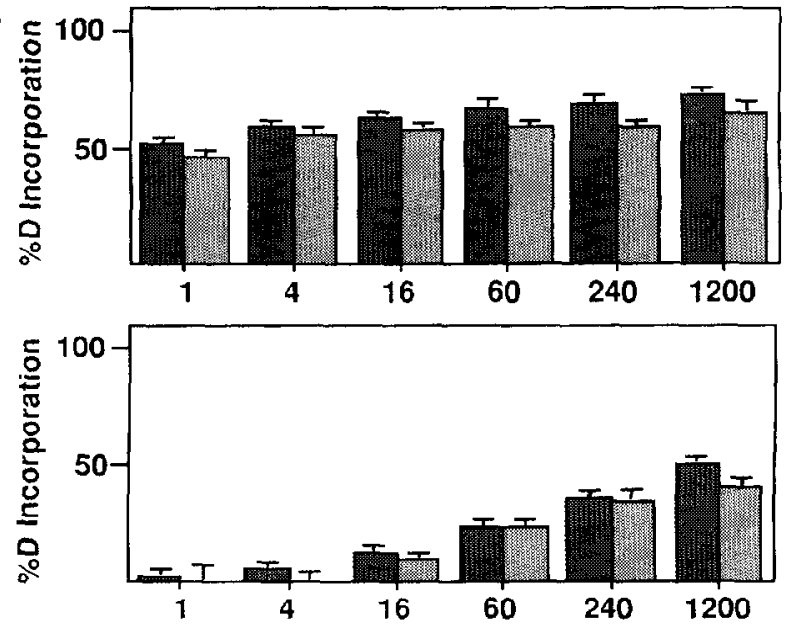

d

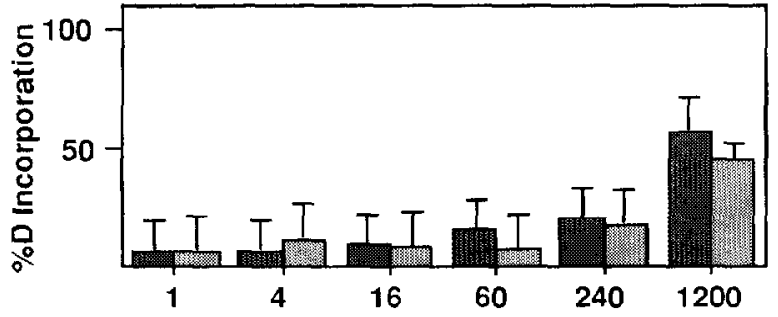

e

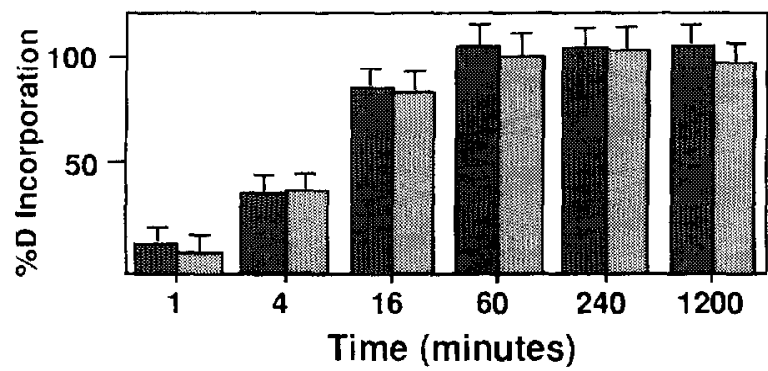

Figure 4. Peptides derived from the wild-type E. coli HPr (dark bars) and S46D mutant (light bars) that did not exhibit substantial differences in deuterium incorporation rates. These peptides encompass positions (a) 1-5, (b) 6-21, (c) 63-77, (d) 78-80, and (e) 81-85. See the Methods section for experimental details.

\section{Discussion}

Although the measurement of deuterium incorporation into cytochrome $c$ mutants by mass spectrometry was the subject of a previous study [24], the focus of this work is to determine the sensitivity of ESI/MS measurements of deuterium incorporation toward minor changes in protein conformation and/or dynamics, specifically with respect to changes in the $\Delta G$ of folding. An earlier study demonstrated that the $5.5-\mathrm{kcal} /$ mol difference in $\Delta G$ of folding between apo- and 
a

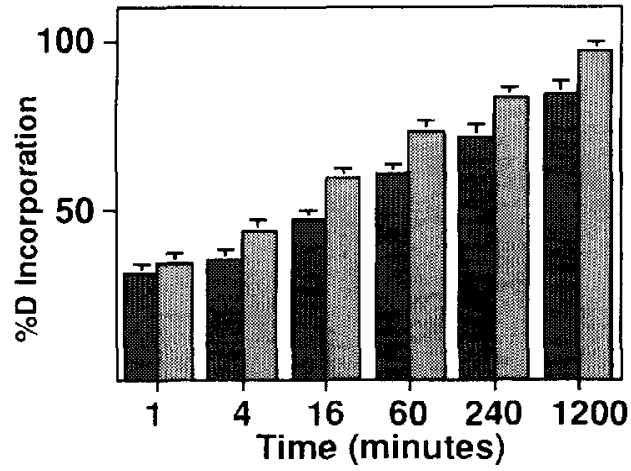

b

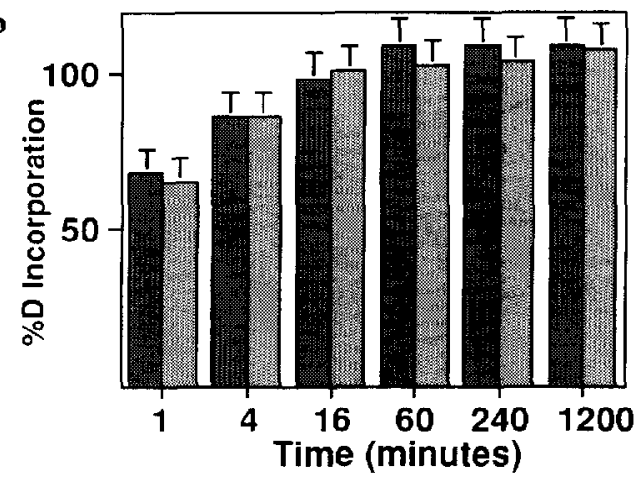

Figure 5. Comparison of the percent deuterium incorporation for two of the peptides derived from the wild-type E. coli HPr (dark bars) and S31A mutant (light bars). These peptides encompass positions (a) 33-47 and (b) 48-58. See the Methods section for experimental details.

holomyoglobin [18] could be measured easily at both the intact protein and peptic peptide level [17]. Here it is shown that single point mutations that result in 1.5and $0.5-\mathrm{kcal} / \mathrm{mol}$ changes in the $\Delta G$ of folding for HPr can be measured readily for peptic peptides obtained from the partially deuterated samples. Measurements on the intact proteins, however, could not distinguish between the wild-type and mutant forms, which suggests that there is an overwhelming background of deuterium incorporation that obscures the few amides that exhibit altered hydrogen exchange rates. Dissection of the partially labeled protein via peptic digestion appears to remove much of that background.

The results obtained for the two mutants are summarized in Figure 6. In both cases, the point mutation seemed to affect only a contiguous region that contained the mutation site; no global effects that influence the entire molecule could be detccted. Peptides that encompass positions 59-62 were not recovered, which perhaps was due to production by pepsin of small peptides that did not bind to the reversed-phase column.

A comparison of the mass spectral deuterium incorporation data with NMR-derived amide hydrogen exchange rates is fairly consistent. NMR studies indicate that no gross conformational changes occur in the S46D mutant (relative to the wild-type protein) and that differences in amide hydrogen exchange rates

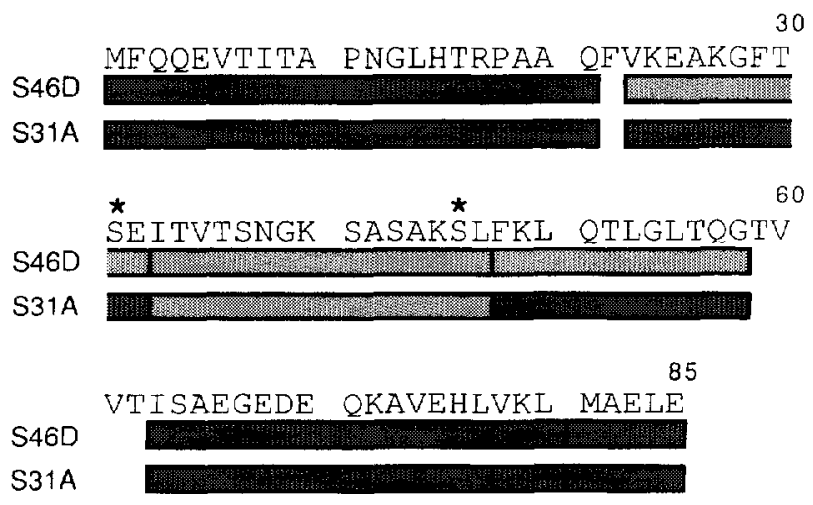

Figure 6. HPr peptic peptide summary. Those peptides derived from either the $\mathrm{S} 46 \mathrm{D}$ or $\mathrm{S} 31 \mathrm{~A}$ mutants that exhibited a significant change in deuterium incorporation rates relative to wild-type HPr from E. coli are shown as light colored bars; those that did not change are shown as darker bars. Mutation sites at positions 31 and 46 are indicated by asterisks.

most likely are due to altered protein dynamics ( $R$. Thapar and R. Klevit, personal communication). The greatest changes in amide hydrogen exchange rates observed by NMR (S46D versus wild type) occur within two of the three regions identified by ESI/MS (residues 33-47 and 48-58; see Figure 3). Additional changes in the slowest exchanging amides may have occurred, but were not measured by NMR. The published NMR structure of wild-type E. coli HPr [25] indicates that the peptide that encompasses positions 48-58 is comprised of an unstructured solvent exposed loop, which explains the very rapid incorporation of deuterium within this region that was observed by both ESI/MS and NMR (Figure 7a). Likewise, the Nand C-terminal regions (positions 1-5 and 81-85) would be expected to be particularly dynamic, that is, to undergo considerable "fraying," and rapid deuterium incorporation was in fact observed by ESI/MS (Figures $4 a$ and e).

Although there is a general consistency between NMR and mass spectral data in this study, the match is not always exact. Whereas the ESI/MS data for the peptides 1-5, 23-32, 48-58, and 81-85 fit quite well with the NMR-derived amide hydrogen exchange data, peptides $6-21,33-47,63-77$, and 78-80 did not (e.g., Figure 7). For example, by NMR residues 79 and 80 have half-lives of 186 and $363 \mathrm{~min}$, respectively [25]. Use of these data enables a percent deuterium incorporation curve to be derived, which does not match the results obtained by ESI/MS (Figure 7b). For this peptide, the observed mass spectral data indicate a slower deuterium incorporation rate than the rate predicted from the NMR results. The source of these inconsistencies is unknown, although it should be pointed out that the NMR and mass spectrometric experiments were performed at slightly different $\mathrm{pH}$ values (the NMR experiments were performed at $\mathrm{pH} 6.5$, whereas here the measured $\mathrm{pH}$ was 6.8 ). Furthermore, ESI/MS measures total deuterium incorporation, whereas NMR 


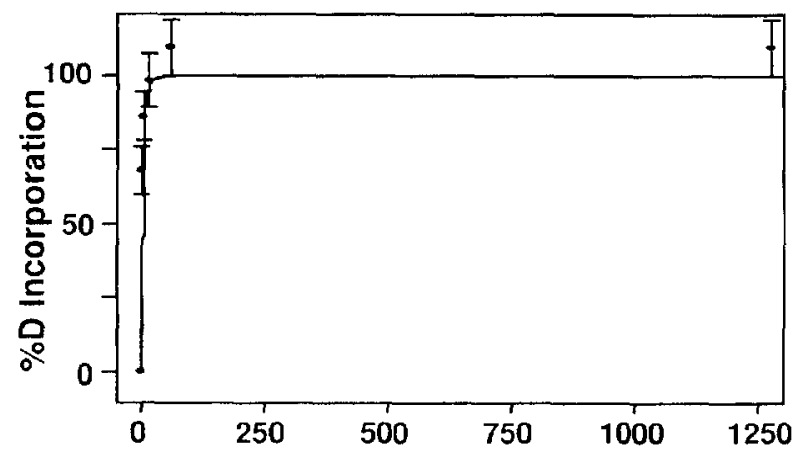

b

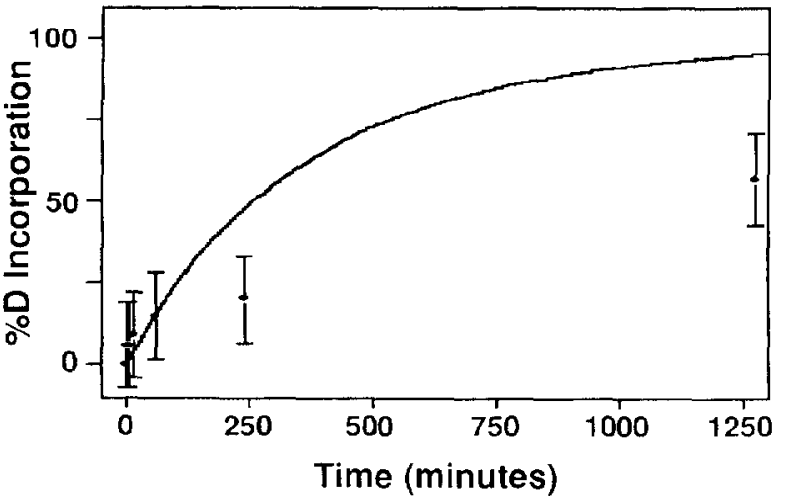

Figure 7. A comparison of NMR and ESI/MS deuterium incorporation. The curves were derived from NMR data [25] and the data points and error bars represent mass spectral measurements of deuterium incorporation (from Figures $3 c$ and $4 d$ ). (a) The peptide that encompasses positions 48-58 contained only one amide hydrogen exchange rate that could be measured by NMR (leucine-53 had a half-life of $10 \mathrm{~min}$ ); the remaining amide hydrogens' exchange rates were too rapid to be measured. To calculate the incorporation curve these latter hydrogens were assumed to have half-lives of $2 \mathrm{~min}$. (b) For the peptide 78-80, the amide hydrogens at positions 79 and 80 were reported to have half-lives of 186 and $363 \mathrm{~min}$, respectively.

data were reported only for main-chain amides. The $\varepsilon$-amino group of lysine and the $\mathrm{N} \delta \mathrm{H}$ of arginine have half-lives of a few minutes at low $\mathrm{pH}$ and $0{ }^{\circ} \mathrm{C}[26,27]$. Likewise, a base-catalyzed reaction at elevated temperatures may label the $\mathrm{C}-2$ hydrogen of histidine, which at low $\mathrm{pH}$ and temperature is quite stable [28]. Thus, the ESI/MS experiments could be measuring a composite of main-chain amide and side-chain functional group hydrogen exchange. In the case of the tripeptide $78-80$, the $\varepsilon$-amino group of lysine-79 may be protected from exchange in the native state, but the mass of the fully deuterated control would include deuterium on this site. Thus the denominator in eq 1 would be artifactually high. Perhaps for these reasons, NMR and ESI/MS results may not be directly comparable.

\section{Conclusion}

It is apparent from these studies that mass spectrometric measurement of amide hydrogen exchange kinetics can be a sensitive probe for relatively minor changes (i.e., $\Delta \Delta G>0.5 \mathrm{kcal} / \mathrm{mol}$ ) in noncovalent protein structure and dynamics that result from point mutations. The method is more widely applicable and uses less material than more rigorous structural characterizations by NMR or crystallography, and it provides more discriminating information than can be derived from more widely used techniques such as circular dichroism or fluorescence spectroscopy. In addition to the study of mutant proteins, this technique should be equally sensitive to many other structural perturbations that result from, for example, posttranslational modifications, ligand binding, and protein-protein interactions

\section{Acknowledgments}

The author thanks Dr. K. Walsh, in whose laboratory this work was performed, and Dr. R. Klevit for providing samples of recombinant wild-type and mutant $\mathrm{HPr}$ and for helpful discussions relating to this work. These studies were supported by the University of Washington Royalty Research Fund.

\section{References}

1. Fenn, J. B.; Mann, M.; Meng, C. K.; Wong, S. F.; Whitehouse, C. M. Science 1989, 246, 64-71.

2. Katta, V.; Chait, B. T. Rapid Commun. Mass Spectrom. 1991, 5, 214-217.

3. Katta, V.; Chait, B. T. J. Am. Chem. Soc. 1993, 115, 6317-6321.

4. Miranker, A.; Robinson, C. V.; Radford, S. E.; Aplin, R. T.; Dobson, C. M. Science 1993, 262, 896-899.

5. Robinson, C. V.; Grob, M.; Eyles, S. J.; Ewbank, J. J.; Mayhew, M.; Hartl, F. U.; Dobson, C. M.; Radford, S. E. Nature 1994, $372,646-651$.

6. Muir, T. W.; Williams, M. J.; Kent, S. B. H. Anal. Biochem. 1995, 224, 100-109.

7. Anderegg, R. J.; Wagner, D. S. J. Am. Chem. Soc. 1995, 117 , 1374-1377.

8. Anderegg, R. J.; Wagner, D. S.; Stevenson, C. L.; Borchardt, R. T. J. Am. Soc. Mass Spectrom. 1994, 5, 425-433.

9. Johnson, R. S.; Krylov, D.; Walsh, K. A. J. Mass Spectrom. 1995, 30, 386-387.

10. Suckau, D.; Shi, Y.; Beu, S. C.; Senko, M. W.; Quinn, J. P.; Wampler, F. M.; McLafferty, F. W. Proc. Natl. Acad. Sci. USA $1993,90,790-793$

11. Zhang, Z.; Smith, D. L. Protein Sci. 1993, 2, 522-531.

12. Rosa, J. J.; Richards, J. M. J. Mol. Biol. 1979, 133, 399-416.

13. Englander, J. J.; Rogero, J. R.; Englander, S. W. Anal. Biochem. 1985, 147, 234-244.

14. Liu, Y.; Smith, D. L. J. Am. Soc. Mass Spectrom. 1994, 5, $19-28$.

15. Zhang, Z.; Post, C. B.; Smith, D. L. Proceedings of the 42nd ASMS Conference on Mass Spectrometry and Allied Topics; 1994; p 903.

16. Ng, J.; Smith, D. L. Proceedings of the $42 n d$ ASMS Conference on Mass Spectrometry and Allied Topics; 1994; 906.

17. Johnson, R. S.; Walsh, K. A. Protein Sci. 1994, 3, 2418.

18. Griko, Y. V.; Privalov, P. L.; Venyaminov, S. Y.; Kutyshenko, V. P. J. Mol. Biol. 1988, 202, 127-138.

19. Chien, N. C.; Roberts, V. A.; Giusti, A. M.; Scharff, M. D.; Getzoff, E. D. Proc. Natl. Acad. Sci. USA 1989, 86, 5532-5536.

20. Schimmel, P. Biochemistry 1990, 29, 9495-9501.

21. Mei, B.; Zalkin, H. J. Biol. Chem. 1989, 264, 16613-16619. 
22. Meadow, N. D.; Fox, D. K.; Roseman, S. Ann. Rev. Biochem. 1990, 59, 497-542.

23. Hammen, P. K.; Scholtz, J. M.; Anderson, J. W.; Waygood, E. B.; Klevit, R. E. Protein Sci. 1995, 4, 936-944.

24. Jaquinod, M.; Halgand, F.; Caffrey, M.; Saint-Pierre, C.; Gagnon, J.; Fitch, J.; Cusanovich, M.; Forest, E. Rapid Commun. Mass Spectrom. 1995, 9, 1135-1140.

25. Hammen, P. K.; Waygood, E. B.; Klevit, R. E. Biochemistry 1991, 30, 11842-11850.
26. Bai, Y.; Milne, J. S.; Mayne, L.; Englander, S. W. Proteins: Structure, Function, and Genetics 1993, 17, 75-86.

2\%. Creighton, T. E. Proteins: Structure and Molecular Properties, 2nd ed.; W. H. Freeman and Company: New York, 1993; pp 282-286.

28. Gregory, R. B.; Rosenberg, A. In Methods in Enzymology, Vol. 131; Hirs, C. H. W.; Timasheff, S. N., Eds.; Academic Press: Orlando, 1986; pp 448-508. 